\title{
Methicillin-Resistant Staphylococcus aureus Associated with Mobile Phones
}

\author{
Sanjib Adhikari ${ }^{1}$, Sujan Khadka ${ }^{1,2^{*}}$, Sanjeep Sapkota ${ }^{1}$, and Pabitra Shrestha ${ }^{1}$ \\ ${ }^{1}$ Department of Microbiology, Birendra Multiple Campus, Tribhuvan University, Chitwan, Nepal \\ ${ }^{2}$ Department of Life Sciences, Biochemistry and Molecular Biology, Central China Normal University, Wuhan, Hubei, P. R. \\ China
}

Received: December 22, 2017; Accepted: March 19, 2018; Published: March 28, 2018

*Corresponding author: Sujan Khadka, Department of Microbiology, Birendra Multiple Campus, Tribhuvan University, Chitwan, Nepal, E-mail: sukha11@mails.ccnu.edu.ch

\begin{abstract}
Mobile phones widely used in our day-to-day lives are potential reservoir for a number of bacteria including Staphylococcus aureus. The study was carried out from February to May 2017 with a major objective of screening methicillin-resistant $S$. aureus (MRSA) from mobile phones used by the staffs and students of Birendra Multiple Campus, Bharatpur, Nepal. Out of 212 swabbed samples of mobile phones analysed by standard microbiological technique, 112 (56.0\%) showed the presence of $S$. aureus. Gentamicin 101 (90.2\%) was the most effective antibiotic whereas cefoxitin $42(37.5 \%)$ was the least effective antibiotic. MRSA 30 (26.8\%), Vancomycin Intermediate S. aureus (VISA) 58 (51.8\%) and MDR S. aureus 24 (21.4\%) were detected. Significant associations were noted between the rate of occurrence of MRSA and MDR S. aureus with various attributes such as the gender of the user, the way of handling the mobile phones and also with the length of use of mobile phones $(P$-value $<0.01)$. Our findings indicate the mobile phones can carry potentially threatening species of $S$. aureus which can cause severe health hazards to humans. Awareness about regular disinfection of mobile phones, hand hygiene, restricting the use of mobile phones in contaminating areas and proper place for storing mobile phones can be suggested.
\end{abstract}

Keywords: MDR; Mobile phones; MRSA; VISA

\section{Introduction}

The users of mobile phones are increasing day by day with 4.61 billion users in 2017 and is anticipated to become 5.07 billion in the year 2019 [https://www. statista. com/statistics/274774/ forecast-of-mobile-phone-users-worldwide/]. S. aureus is the commensal flora of several animals and humans [1]. The fact that mobile phone could create a key health hazard has been revealed by several researches. Because of the dual effect of constant handling and the heat generated by the phones, mobile phones provide a major breeding ground for all sorts of microorganisms that are normally found on the human skin [2]. The surface area of an adult human skin is about $2 \mathrm{~m}^{2}$ harboring about $10^{12}$ bacterial cells/person [3]. The mobile phone comes into contact with contaminated human body parts with hands to hands, and hands to other parts like mouth, nose and ears, during the phone call [4].
Mobile phones may harbor different pathogenic bacteria because they are commonly handled regardless of the sanitation of hands and hardly disinfected [5]. The use of such mobile phone serves as a potential vehicle for the spread of nosocomial pathogens including multidrug-resistant pathogens such as MRSA [6].

In recent years, community-acquired MRSA (CA-MRSA) strains, the rapidly becoming dominant pathogens in the community, have emerged [3]. Vancomycin is the antibiotic for the treatment of MRSA cases but several reports have shown that MRSA intermediate and resistant patterns against vancomycin and treatment of MRSA cases with vancomycin is extremely problematic $[7,8]$. Presence of such pathogenic bacteria like MRSA, VISA and MDR S. aureus in mobile phones can indicate the immediate medical attention to abate this issue.

Although the contamination of mobile phones of health workers has been studied, little information regarding the contamination of personal mobile phones of people in the community exists. Bacterial flora on cell phones may vary in composition, number and antibiotic sensitivity from person to person. This is probably the first study in Nepal that attempts to explore the bacterial flora present on the mobile phones in community samples and their antimicrobial susceptibility patterns.

In this study, we have identified MRSA, VISA and MDR $S$. aureus from mobile phones used by the students and the staffs and also have drawn a significant association between various attributes of users and mobile phones with the isolation rate of S. aureus.

\section{Materials and Methods \\ Study design and sample size}

This cross-sectional study was carried out in Birendra Multiple Campus, Bharatpur amongst its staffs and students from February to May, 2017. During the period, altogether 200 mobile phone swabs were collected and the laboratory analyses 
were performed at the Microbiology laboratory of the Campus. A semi-structured questionnaire was used to extract data on age, gender and status of each participant. In addition, it also included information regarding the type of mobile phone used, its length of the use by owner, habit of disinfection, practice of handling the mobile phone such as place of storing and its use in toilets.

\section{Culture of Specimen}

Screens and keypads of mobile phones were swabbed with the sterile cotton swabs soaked in normal saline and immersed in peptone water and left for incubation at $37^{\circ} \mathrm{C}$ for 24 hours. On the following day, a loopful of the growth was streaked on MSA and again incubated for 24 hours at $37^{\circ} \mathrm{C}$. Yellow colonies on MSA showing violet color with grapes like clusters on Gram's staining were sub-cultured on NA and BA [9]. Further, hemolysis was observed on blood agar for the identification of $S$. aureus.

\section{Identification of Isolates}

Those colonies from NA giving positive Gram's reaction were further tested for oxidase, catalase, coagulase, DNase and oxidative/fermentative tests for the confirmation of $S$. aureus. Production of beta-hemolysis on blood agar indicated the presence of $S$. aureus [9].

\section{Antibiotic Susceptibility Test}

Antibiotic susceptibility tests were performed by the disc diffusion method recommended by Clinical and Laboratory Standards Institute using Mueller Hinton Agar [10]. Firstly, MHA plates were swabbed by a bacterial suspension in sterile normal saline comparable to 0.5 McFarland turbidity standards. Using sterile tweezers, antimicrobial discs such as tetracycline (30 mcg), gentamicin (10mcg), cloxacillin (5mcg), amikacin (30 mcg), erythromycin $(10 \mathrm{mcg})$, vancomycin $(10 \mathrm{mcg})$, cefoxitin ( $30 \mathrm{mcg})$, cotrimoxazole $(15 \mathrm{mcg})$, ciprofloxacin $(5 \mathrm{mcg})$ and ceftriazone $(30 \mathrm{mcg})$ were placed widely spaced aseptically on the surface of MHA plate. Tweezers were re-flamed after application of each disc. The plates were then incubated at $37^{\circ} \mathrm{C}$ for 24 hours. Following incubation, the diameter of inhibition zone were measured with a transparent ruler and expressed in millimeter (mm). AST was performed for all the bacterial isolates. Multidrug resistance was defined as resistance to three or more of the antimicrobial agents belonging to different structural classes [11]. For the identification and standardization of the Kirby-Bauer test, standard culture of S. aureus ATCC 25923 was used as a reference strain.

\section{Statistical analysis}

Data were tabulated and analyzed by using SPSS version 20. $P$-values less than 0.01 were considered to have significant association.

\section{Ethical Considerations}

This study was approved by the Department of Microbiology, Birendra Multiple Campus. A questionnaire was used to collect personal as well as behavioral data. The questionnaire was arranged based on previous studies and according to the authors' own insights of probable factors that could contribute to the contamination of mobile phones. Informed consent was taken from the staffs and students of Birendra Multiple Campus prior to collecting samples and filling the structured questionnaire.

\section{Results}

Out of 200 mobile phones swabbed, bacterial growth was found on $112(56.0 \%)$ samples. Of the 10 different antibiotics used, gentamicin $101(90.2 \%)$ was found to be the most effective followed by amikacin 95 (84.8\%). In contrast, cefoxitin 42 (37.5\%) was the least active antibiotic. Thirty (26.8\%) bacterial isolates were detected as Methicillin Resistant S. aureus (MRSA) whereas $58(51.8 \%)$ bacterial isolates were found to be Vancomycin Intermediate $S$. aureus (VISA) and $24(21.4 \%)$ isolates were Multiple Drug Resistant (MDR) (Table 1).

\begin{tabular}{|c|c|c|c|c|c|c|c|c|c|c|}
\hline \multirow[t]{2}{*}{ S No } & \multirow[t]{2}{*}{ Antibiotics } & \multicolumn{6}{|c|}{$\begin{array}{l}\text { Antibiotic Susceptibility Test } \\
\text { (By Disc Diffusion Method) }\end{array}$} & \multirow[t]{2}{*}{ MDR } & \multirow[t]{2}{*}{$\%$} & \multirow[t]{2}{*}{ Isolates } \\
\hline & & Sensitive & $\%$ & Intermediate & $\%$ & Resistant & $\%$ & & & \\
\hline 1 & Amikacin & 95 & 84.8 & 7 & 6.3 & 10 & 8.9 & \multirow{10}{*}{24} & \multirow{10}{*}{21.4} & \multirow{10}{*}{112} \\
\hline 2 & Cefoxitin & 42 & 37.5 & 40 & 35.7 & 30 & 26.8 & & & \\
\hline 3 & Ceftriazone & 65 & 58 & 29 & 25.9 & 18 & 16.1 & & & \\
\hline 4 & Ciprofloxacin & 91 & 81.3 & 5 & 4.5 & 16 & 14.3 & & & \\
\hline 5 & Cloxacillin & 61 & 54.5 & 38 & 33.9 & 13 & 11.6 & & & \\
\hline 6 & Cotrimoxazole & 90 & 80.4 & 16 & 14.3 & 6 & 5.4 & & & \\
\hline 7 & Erythromycin & 61 & 54.5 & 25 & 22.3 & 26 & 23.2 & & & \\
\hline 8 & Gentamicin & 101 & 90.2 & 7 & 6.3 & 4 & 3.6 & & & \\
\hline 9 & Tetracycline & 90 & 80.4 & 10 & 8.9 & 12 & 10.7 & & & \\
\hline 10 & Vancomycin & 54 & 48.2 & 58 & 51.8 & - & - & & & \\
\hline
\end{tabular}


Significant association was noted between the occurrence of bacterial isolates and various attributes. Mobile phones used in toilets and used for more than 2 years were found to be heavily contaminated by $S$. aureus, MRSA and MDR isolates ( $P$-value < 0.01 ) whereas practice of disinfecting the mobile phones reduced their rates of isolation $(P$-value $<0.01)$ (Table 2).
The number of MRSA isolates was quite higher in the mobile phones carried in pockets than those carried in mobile-bags (P-value $<0.01)$ (Table 3). A significant association was observed between the presence of MDR isolates and the gender of the users. A large number of MDR S. aureus 16 (66.7\%), was detected from the mobile phones used by females compared to those used by males $8(33.3 \%)(P$-value $<0.01)$ (Table 4$)$.

Table 2: Association between the rate of isolation of bacterial isolates with several characteristics of users and mobile phones

\begin{tabular}{|c|c|c|c|c|c|}
\hline SN & \multicolumn{2}{|c|}{ Attributes } & Growth & $\%$ & P-value \\
\hline \multirow{2}{*}{1} & \multirow{2}{*}{ Gender } & Male & 59 & 52.7 & \multirow{2}{*}{0.085} \\
\hline & & Female & 53 & 47.3 & \\
\hline \multirow{3}{*}{2} & \multirow{3}{*}{ Age } & $11-20$ & 20 & 17.1 & \multirow{3}{*}{0.49} \\
\hline & & $21-30$ & 64 & 57.9 & \\
\hline & & $31-40$ & 28 & 25 & \\
\hline \multirow{2}{*}{3} & \multirow{2}{*}{ Status } & Student & 61 & 54.5 & \multirow{2}{*}{0.191} \\
\hline & & Staff & 51 & 45.5 & \\
\hline \multirow{2}{*}{4} & \multirow{2}{*}{ Mobile phones types } & Screen-touch & 97 & 86.6 & \multirow{2}{*}{0.085} \\
\hline & & Keypad & 15 & 13.4 & \\
\hline \multirow{2}{*}{5} & \multirow{2}{*}{ Used in toilet } & Yes & 67 & 59.8 & \multirow{2}{*}{$<0.01$} \\
\hline & & No & 45 & 40.2 & \\
\hline \multirow{2}{*}{6} & \multirow{2}{*}{ Disinfectant used } & Yes & 55 & 49.1 & \multirow{2}{*}{$<0.01$} \\
\hline & & No & 57 & 50.9 & \\
\hline \multirow{2}{*}{7} & \multirow{2}{*}{ Storage of mobile phones } & Clothes & 72 & 64.3 & \multirow{2}{*}{0.163} \\
\hline & & Bag & 40 & 35.7 & \\
\hline \multirow{3}{*}{8} & \multirow{3}{*}{ Age of mobile phones (Months) } & $01-12$ & 23 & 20.5 & \multirow{3}{*}{$<0.01$} \\
\hline & & $13-24$ & 44 & 39.3 & \\
\hline & & More than 24 & 45 & 40.2 & \\
\hline
\end{tabular}

Table 3: Association between rate of isolation of MRSA with several characteristics of users and mobile phones

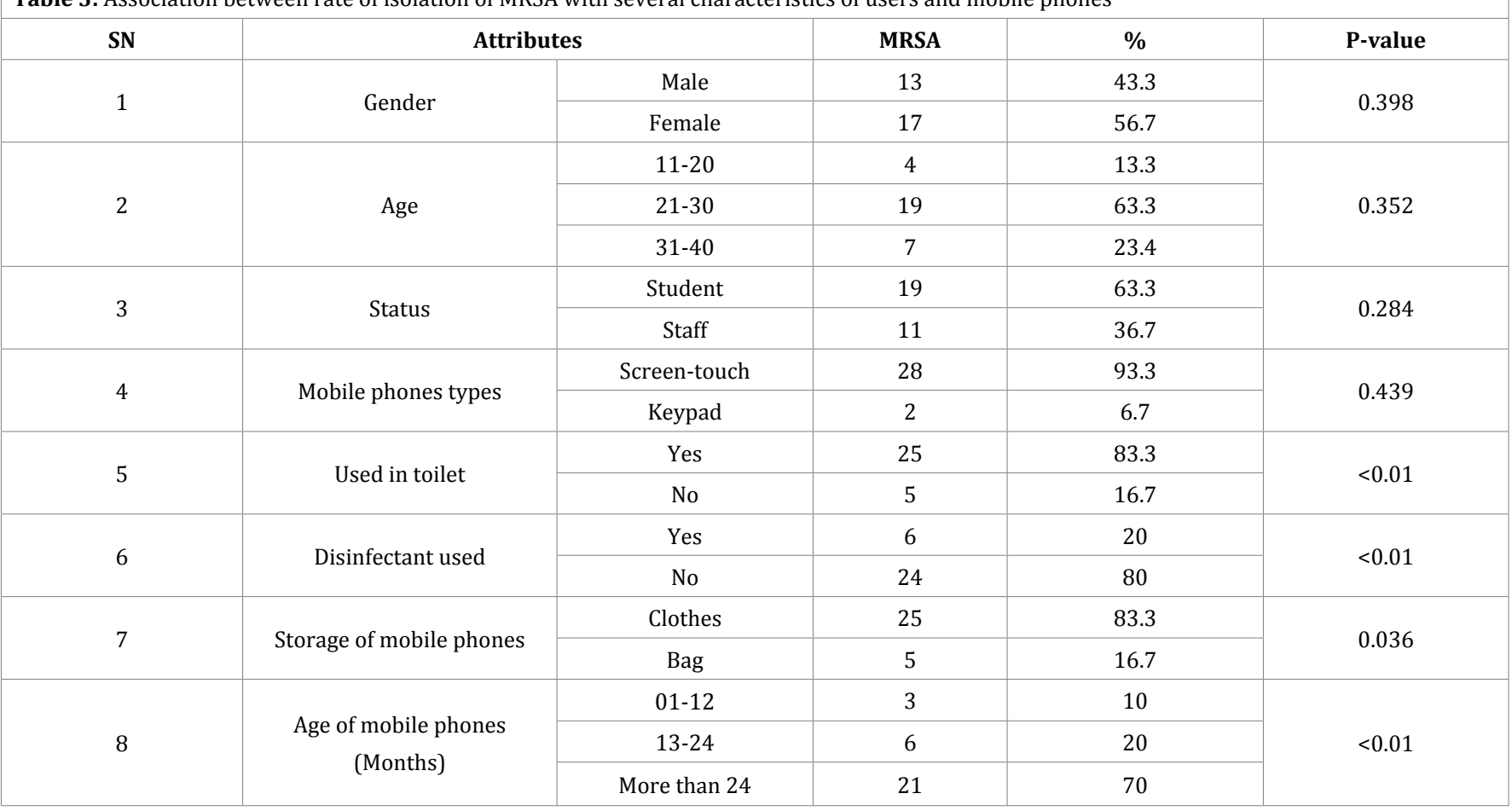

Citation: Sanjib A, Sujan K, Sanjeep S, Pabitra S (2018) Methicillin-Resistant Staphylococcus aureus Associated with Mobile Phones $\quad$ Page 3 of 6 SOJ Microbiol Infect Dis 6(1):1-6. 


\begin{tabular}{|c|c|c|c|c|c|}
\hline SN & \multicolumn{2}{|c|}{ Attributes } & MDR & $\%$ & P-value \\
\hline \multirow{2}{*}{1} & \multirow{2}{*}{ Gender } & Male & 8 & 33.3 & \multirow{2}{*}{$<0.01$} \\
\hline & & Female & 16 & 66.7 & \\
\hline \multirow{3}{*}{2} & \multirow{3}{*}{ Age } & $11-20$ & 3 & 12.5 & \multirow{3}{*}{0.282} \\
\hline & & $21-30$ & 17 & 70.8 & \\
\hline & & $31-40$ & 4 & 16.7 & \\
\hline \multirow{2}{*}{3} & \multirow{2}{*}{ Status } & Student & 17 & 70.8 & \multirow{2}{*}{0.191} \\
\hline & & Staff & 7 & 29.2 & \\
\hline \multirow{2}{*}{4} & \multirow{2}{*}{ Mobile phones types } & Screen-touch & 22 & 91.7 & \multirow{2}{*}{0.208} \\
\hline & & Keypad & 2 & 8.3 & \\
\hline \multirow{2}{*}{5} & \multirow{2}{*}{ Used in toilet } & Yes & 22 & 91.7 & \multirow{2}{*}{$<0.01$} \\
\hline & & No & 2 & 8.3 & \\
\hline \multirow{2}{*}{6} & \multirow{2}{*}{ Disinfectant used } & Yes & 2 & 8.3 & \multirow{2}{*}{$<0.01$} \\
\hline & & No & 22 & 91.7 & \\
\hline \multirow{2}{*}{7} & \multirow{2}{*}{ Storage of mobile phones } & Clothes & 12 & 50 & \multirow{2}{*}{0.19} \\
\hline & & Bag & 12 & 50 & \\
\hline \multirow{3}{*}{8} & \multirow{3}{*}{$\begin{array}{l}\text { Age of mobile phones } \\
\text { (Months) }\end{array}$} & 12-Jan & - & - & \multirow{3}{*}{$<0.01$} \\
\hline & & $13-24$ & 5 & 20.8 & \\
\hline & & More than 24 & 19 & 79.2 & \\
\hline
\end{tabular}

\section{Discussion}

In the present study, $56.0 \%$ of the mobile phones were found to harbor $S$. aureus. This finding is $16.5 \%$ lower than the growth rate of MSSA (methicillin susceptible $S$. aureus) on mobile phones used by non-health workers and almost $25.0 \%$ lowers than S. aureus (both MSSA and MRSA) on the mobile phones used by health care workers as reported by Chawla et al [12]. Similarly, in our finding the rate of contamination of mobile phones by $S$. aureus was found to be higher than the figures reached by studies on $S$. aureus contamination of mobile phones of health workers conducted in Palestine (27.0\%) by Elmanama et al [13]; in Turkey $(52.0 \%)$ by Ulger et al [14]; in Ethiopia (21.0\%) by Gashaw et al [15] and in Nigeria (50.0\%) by Ilusanya et al [16]. Unlike the work by Chawla et al [12] who reported none of the bacterial isolates from mobile phones used by health-workers in India developed drug resistance, our findings identified 30 (26.8\%) of the bacterial isolates were methicillin resistant and 24 (21.4\%) were multiple drug resistant.

Elkholy et al reported $31.0 \%$ S. aureus isolated from mobile phones were methicillin resistant [4]. A report by Heyba et al. showed that MRSA was identified in $3(1.4 \%)$ mobile phones among which none was resistant to vancomycin [17]. In our work, $26.8 \%$ of $S$. aureus were found to be resistant against cefoxitin which is nearly similar to a study conducted by Kuhu Pal et al, who showed almost $21.0 \%$ of $S$. aureus isolated from mobile phones were resistant to cefoxitin [18]. None of the S. aureus isolates was noted to be resistant against vancomycin in Kuhu
Pal's work which is consistent with our study. Similarly, Chawla et al also reported the presence of $20.0 \%$ of MRSA on the mobile phones used by health care workers in teaching institution, Manipal, Karnataka, India. But no MRSA was detected from nonhealth workers' mobile phones in their study [12]. Similarly, in India, Bhat et al identified 40.0\% MRSA and 58.6\% MSSA from mobile phones of medical personnels [19]. In health care settings, MRSA can cause terrible consequences. It can cause bloodstream infections, if not treated properly it can also result sepsis and even deaths [https://www. cdc. gov/mrsa/healthcare/index. html]. In another study, Kuhu Pal revealed that conventional keypad phones $(94.4 \%)$ were greatly contaminated than touchscreen phones $(67.8 \%)$ by $S$. aureus and other microorganisms as well [18]. In contrast, in our study, $86.6 \%$ of touch-screen phones and $13.4 \%$ of keypad phones were found to be contaminated by S. aureus.

In our study, $37.0 \%$ users were found to have never used any disinfectants in their mobile phones. This figure is quite lesser than a research carried out by Sadat-Ali in Saudi Arabia who reported that $76.0 \%$ of the clinicians had never disinfected their mobile phones [20]. Similarly, a work done at one of the hospitals in Kuwait by Heyba et al pointed out that $66.5 \%$ of the participants had never disinfected their mobile phones [17]. Microbial contaminations are the risks related with the irregular cleaning of phones [21]. Our study shows a significant association between the disinfection process and the rate of contamination by $S$. aureus $(P$-value $<0.01)$, MRSA $(P$-value $<0.01)$ and MDR $S$. aureus $(P$-value $<0.01)$. 
The rate of incidence of contamination of mobile phones held by females in IUG (Islamic University of Gaza) (52.0\%) was lower than that of male counterparts (79.0\%) [13]. Auhim's findings in Iraq were consistent with this, which showed that the rate of bacterial contamination of personal mobile phones of males was $85.0 \%$ compared with $80.0 \%$ of females [22]. Similarly, in the present study, we observed a higher rate of incidence of bacterial contamination in the mobile phones carried by males $(52.7 \%)$ than those carried by the females (47.3\%). We also noted a significant association between the isolation rate of MDR $S$. aureus and gender of the users $(P$-value $<0.01)$. Female users had their mobile phones more contaminated with MDR S. aureus than the males. In a research work performed by Salha H. M and Al-Zahrani in 2012, it was found that fingernails can also harbor MDR S. aureus [23]. Females usually keep longer nails which can directly transmit MDR $S$. aureus to the mobile phones while using. In a study presented in a meeting of the Infectious Disease Society of America in San Francisco, researchers showed that artificial and natural nails longer than 3 millimeters beyond the tip of the finger, or the length of a pencil tip, transport more harmful bacteria and yeast under them as compared to the short nails (http://abcnews. go. com/Health/story?id=117161).

Akinyemi et al concluded that $S$. aureus was the most encountered bacterial agent, probably because this type of bacteria proliferates in optimum temperatures, as phones are kept warm in pockets, handbags and brief cases [24]. Our study reveals that $83.3 \%$ MRSA were isolated from the mobile phones carried in the pants and shirts and only $5(16.7 \%)$ bacteria were isolated from mobile phones carried in bags. A study conducted by Kuhu Pal illustrated that a large number of users carry their phones in clothes than in bags but in his study the rate of contamination was found to be higher in mobile phones stored in bags (95.4\%) than those carried in clothes (84.6\%) [18]. Converesly, in our study, $64.3 \%$ of $S$. aureus were isolated from the mobile phones stored in the pocket which was $28.6 \%$ higher than those isolated from mobile phones stored in the bags. This may be because users frequently put their hands inside the pockets than inside the bags which can increase the chances of transmission of $S$. aureus through their hands on the mobile phones kept inside the pockets. There was no significant association between the rates of isolation of MDR $S$. aureus and the storage of mobile phones $(P$-value $>0.01)$ in our study. Similarly, no significant association was noted in the study conducted by Kuhu Pal regarding the rate of isolation $S$. aureus and storage of mobile phones ( $P$-value > 0.01) [18].

A study conducted by Zakai et al revealed that $59.0 \%$ medical students used their mobile phones in the toilets [25]. This finding is comparatively higher than our study in which $40.2 \%$ of the respondents used their mobile phones in toilets. Mobile phones can act as fomites as they are contaminated by users from areas such as toilets, hospitals and kitchens, which are burdened with microorganisms [26]. Furthermore, Giannini et al reported that hospital's toilets are the source for MRSA [27]. The MRSA are very difficult to kill and are significantly dangerous as stated by San Diego County Health and Human Services Agency which also reported that MRSA is spread by person-to-person contact and is frequently harbored in toilet bowls and dirty environment [https://healthyliving. azcentral. com/bacteriafound-in-toilet-bowls12320100. html]. Using mobile phones in such environments can be one of the reasons for presence of MRSA on the mobile phone surface. It is also revealed in our study that the mobile phones used in the toilets were tremendously contaminated with $S$. aureus $(P$-value $<0.01)$ and also a significant number of MRSA $(P$-value $<0.01)$ and MDR $S$. aureus (P-value < 0.01 ) were found in the mobile phones used in toilets.

Furthermore, in our study, mobile phones used for more than 24 months were found to be highly contaminated with MRSA, VISA and MDR S. aureus. This may be due to the fact that older phones are more hospitable to $S$. aureus for proliferation as they may contain more layers of dusts and sweats compared to the newer phones.

\section{Conclusion}

Occurrence of MRSA, VISA and MDR S. aureus in the mobile phones as observed in the present study can be a potential threat to humans and medical fraternity as well. Therefore, increase in awareness to decontaminate the mobile phones by effective disinfectant would be useful. Proper and judicious use of antibiotic should be recommended to prevent the emergence of MDR bacteria. Using mobile phones in the contaminating areas like toilets should be discouraged. Good hygienic practices of users are necessary in order to prevent cross-contamination.

\section{Author's contribution}

Sujan Khadka, Pabitra Shrestha and Sanjeep Sapkota conceived and designed the study, accomplished the laboratory works and analyzed the data. Sujan Khadka and Sanjib Adhikari drafted the manuscript. Sanjib Adhikari monitored the study. All the authors state that there is no conflict of interests.

\section{Acknowledgement}

The authors would like to appreciate the students and staffs of Birendra Multiple campus for providing mobile phone samples and responding enthusiastically to the questionnaire developed.

\section{References}

1. Vanderhaeghen W, Cerpentier T, Adriaensen C, Vicca J, Hermans K, and Butaye P. Methicillin-resistant Staphylococcus aureus (MRSA) ST398 associated with clinical and subclinical mastitis in Belgian cows. Vet Microbiol. 2010;144(1-2):166-171. DOI: 10.1016/j. vetmic.2009.12.044

2. Brady RRW, Wasson A, Stirling I, McAllister C, and Damani NN. Is your phone bugged? The incidence of bacteria known to cause nosocomial infection on healthcare workers' mobile phones. Journal of Hospital Infection. 2006;62(1):123-125. DOI: 10.1016/j.jhin.2005.05.005

3. Miller L, Gand Diep BA.Colonization, Fomites, and Virulence: Rethinking the Pathogenesis of Community-Associated Methicillin-Resistant Staphylococcus aureus Infection. Clin Infect Dis.2008;46(5):752-760. DOI: $10.1086 / 526773$

4. Elkholy MT, Ewees IE. Mobile (Cellular) Phones Contamination with 
Nosocomial Pathogens in Intensive Care Unit. Med J Cairo Univ. 2010;78(2):1-5.

5. Singh A, Walker M, Rousseau J, Monteith GJ, Weese JS. Methicillinresistant staphylococcal contamination of clothing worn by personnel in a veterinary teaching hospital. Vet Surg. 2013;42(6):643-648. DOI: 10.1111/j.1532-950X.2013.12024.x

6. Selim HS and Abaza AF. Microbial contamination of mobile phones in a health care setting in Alexandria, Egypt. GMS Hyg Infect Control .2015, 10:Doc03. DOI:10.3205/dgkh000246

7. Finks J, Wells E, Dyke TL, Husain N, Plizga L, and Heddurshetti R. Vancomycin-resistant Staphylococcus aureus, Michigan, USA, 2007. Emerg Infect Dis. 2009;15(6):943-945. DOI: 10.3201/eid1506.081312

8. Amatya R, Devkota P, and Gautam A. Reduced susceptibility to Vancomycin in methicillin resistant Staphylococccus aureus : a time for action. Nepal Med Coll J.2014;16:42-44.

9. Forbes BA, Sahm DF, and Weissfeld AS. Bailey and Scott's Diagnostic Microbiology, Mosby, 12th edition, 2007.

10.CLSI, "Performance Standards for Antimicrobial Susceptibility Testing," Twenty-Fifth Informational Supplement. Clinical and Laboratory Standards Institute. 2015;1-184.

11. Magiorakos AP, Srinivasan A, Carey RB, Carmeli Y, Falagas ME, Giske CG, et al. Multidrug-resistant, extensively drug-resistant and pandrugresistant bacteria: an international expert proposal for interim standard definitions for acquired resistance. Clinical Microbiology and Infection. 2012;18(3):268-281. DOI: 10.1111/j.14690691.2011.03570.x

12. Chawla K, Mukhopadhayay C , Gurung B , Bhate P and Bairy I. Bacterial "Cell" phones: Do cell phones carry potential pathogens?. Online J Heal Allied Sci.2009;8(1):1-5.

13. Elmanama A, Hassona I, Marouf A, Alshaer G, and Ghanima EA. Microbial Load of Touch Screen Mobile Phones Used by University Students and Healthcare Staff. J Arab Am Univ. 2015;1(1):1-21.

14. Ulger F, Esen S, Dilek A, Yanik K, Gunaydin M, Leblebicioglu H. Are we aware how contaminated our mobile phones with nosocomial pathogens?" Ann Clin Microbiol Antimicrob. 2009;8(1):7.

15. Gashaw M, Abtew D and Addis Z. Prevalence and Antimicrobial Susceptibility Pattern of Bacteria Isolated from Mobile Phones of Health Care Professionals Working in Gondar Town Health Centers. ISRN Public Health. 2014;1-6.

16. Illusanya OAF, Adesanya 00, Adesemowo A and Amushan N.A. Personal Hygiene and Microbial contamination of Mobile phones of Food vendors in Ago-Iwoye Town, Ogun State, Nigeria. Pakistan Journal of Nurition.2012;11(3):276-278. DOI: 10.3923/pjn.2012.276.278

17. Heyba M, Ismaiel M, Alotaibi A, Mahmoud Baqer H, Safar A, et al. Microbiological contamination of mobile phones of clinicians in intensive care units and neonatal care units in public hospitals in Kuwait. BMC Infect Dis. 2015;15(1):434. DOI: 10.1186/s12879-0151172-9

18. Pal K, Chatterjee M, Sen P, and Adhya S. Cell Phones of Health Care Professionals: A Silent Source of Bacteria. Natl J Lab Med. 2015; 4(4):33-38. DOI: NJLM/2015/13984:2069

19. Bhat SS, Sundeep HK, Salian S. Potential of mobile phones to serve as a reservoir in spread of nosocomial pathogens. Online J Health Allied Scis. 2011;10(2):5-7.

20. Sadat Ali M, Al Omran AK, Azam Q, Bukari H, Al-Zahrani AJ, Al-Turki RA, et al. Bacterial flora on cell phones of health care providers in a teaching institution. Am J Infect Control. 2010;38(5):404-405. DOI: 10.1016/j.ajic.2009.08.007

21. Ramesh J, Carter AO, Campbell MH, Gibbons N, Powlett C, Moseley $\mathrm{H}$ et al. Use of mobile phones by medical staff at Queen Elizabeth Hospital, Barbados: evidence for both benefit and harm. J Hosp Infect.2008;70(2):160-165. DOI: 10.1016/j.jhin.2008.06.007

22. Auhim HS. Bacterial contamination of personal mobile phones in Iraq. J Chem Biol Phys Sci. 2013;3(4):2652-2656.

23. Salha HM Al-Zahrani, "Detection of antibiotic resistant Staphylococcus aureus among male carriers in Jeddah Sites" Nature and Science. $2012 ; 10(2)$.

24. Akinyemi KO, Atapu AD, Adetona OO, Coker AO. The potential role of mobile phones in the spread of bacterial infections. J Infect Dev Ctries. 2009;3(8):628-632.

25.Zakai S, Mashat A, Abumohssin A, Samarkandi A, Almaghrabi B, Barradah $\mathrm{H}$ et al. Bacterial contamination of cell phones of medical students at King Abdulaziz University, Jeddah, Saudi Arabia. J Microsc Ultrastruct . 2016;4(3):143-146.

26. Bhoonderowa A, Gookool S, and Biranjia-Hurdoyal SD. The Importance of Mobile Phones in the Possible Transmission of Bacterial Infections in the Community. J Community Health. 2014;39(5):965-967. DOI: 10.1007/s10900-014-9838-6

27. Giannini MA, Nance D, McCullers JA. Are toilet seats a vector for transmission of methicillin-resistant Staphylococcus aureus? Am J Infect Control. 2009;37(6):505-506. DOI: 10.1016/j.ajic.2008.11.005 